\title{
Disparidades do desenvolvimento urbano e rural: uma análise espacial para as microrregiões do estado de Minas Gerais ${ }^{1}$
}

\author{
Luiz Eduardo Vasconcelos Rocha² \\ Rosa Maria Oliveira Fontes ${ }^{3}$
}

Resumo: As novas dinâmicas econômicas e o aumento da urbanização, que distanciaram a região rural brasileira do contexto exclusivamente das atividades agropecuárias, pautaram a retomada dos debates que procuram delimitar os diferentes níveis de relacionamento entre o rural e o urbano. Dentro deste contexto, o trabalho, a partir do Índice de Desenvolvimento da Família (IDF), analisa o nível de integração das condições de vida das famílias urbanas e rurais das sessenta e seis microrregiões do Estado de Minas Gerais no ano de 2000. Para identificar a estrutura espacial do (IDF) e de suas dimensões utilizou-se o método da Análise Exploratória de Dados Espaciais (AEDE) por meio da estatística I de Moran e da identificação de clusters. As análises demonstraram que as condições de vida e o bem-estar das famílias são condicionados pela realidade socioeconômica e geográfica das regiões em que estão inseridas. Observou-se um quadro de forte desigualdade no desenvolvimento humano das famílias mineiras, tanto no que diz respeito às condições de vida entre as regiões urbana e rural, quanto nas disparidades entre as regiões sul e norte do estado.

Palavras-chave: Desenvolvimento humano; Territórios rural e urbano; Análise exploratória de dados espaciais; Abordagem das capacitações.

\footnotetext{
1 A primeira versão do trabalho foi publicada nos Anais da Conference of the Human and Capability Association - HDCA, realizada em Lima (Peru), 2009. Os autores agradecem à Fundação de Amparo à Pesquisa do Estado de Minas Gerais (FAPEMIG), pelo financiamento da pesquisa; e as sugestões dos pareceristas anônimos da Revista. Os possíveis erros remanescentes são de responsabilidade exclusiva dos autores.

2 Professor Associado do Departamento de Ciências Econômicas da Universidade Federal de São João Del Rei - UFSJ - levrocha@ufsj.edu.br

3 Professora Titular do Departamento de Ciências Econômicas da Universidade Federal de Viçosa - UFV -rfontes@ufv.br
} 


\title{
Urban and rural disparities: spatial analysis of microregions from Minas Gerais state
}

\begin{abstract}
The new economic trends and urbanization development, which increased the distance between the rural areas and the agropecuary activities in Brazil, have rejuvenated the discussion aiming at defining the different levels of relationship between both rural and urban environments. Bearing this context in mind, this project, based on the Family Development Index (FDI), goes on to analyze the integration between the rural and urban level of living standard and life conditions of 66 micro-regions in Minas Gerais state in the year of 200o. In order to identify such FDI spatial structure and its dimensions, the Exploratory Spatial Data Analyses (ESDA) via Statistics I and clusters identification have been used. Such analyses have provided evidence that life conditions and family welfare are founded by the socio-economic and geographic reality within its context. The data analysis has also revealed a substantial level of inequality in the families human development when it comes to both rural and urban regions as well as the disparity between both the South and North regions in the state of Minas Gerais.
\end{abstract}

Keywords: human development; rural and urban regions; exploratory spatial data analysys; capability approach.

\section{Introdução}

As recentes mudanças ocorridas no meio rural brasileiro, caracterizadas pelo surgimento de novas dinâmicas econômicas e pelo aumento da urbanização, que distanciaram a região do contexto exclusivamente das atividades agropecuárias, levaram a retomada dos debates que procuram delimitar os diferentes níveis de relacionamento entre o rural e o urbano. No caso específico dos programas de desenvolvimento rural e das intervenções de políticas públicas, observou-se a manutenção de uma abordagem dicotômica campo-cidade, a qual exclui o espaço urbano, que tem se mostrado cada vez mais responsável pelo dinamismo do meio rural. Em última instância, esses programas e políticas públicas, em vez da visão antagônica campo-cidade, devem buscar ordenar a integração das áreas urbanas com as regiões rurais em seu entorno, dotando o campo de infra-estrutura e serviços que assegurem a diminuição das disparidades das condições de vida entre esses territórios (Graziano \& Grossi 2001).

Dentro deste contexto e da crescente urbanização das áreas rurais, o trabalho pretende analisar o nível de integração das condições de vida das famílias urbanas e rurais das sessenta e seis microrregiões do Estado de Minas Gerais, as quais apresentam grande heterogeneidade socioeconômica e geográfica 
e, de certa forma, sintetizam a realidade socioeconômica do país na medida em que são um caleidoscópio de culturas, costumes, atividades econômicas, condições naturais (clima, geomorfologia, solos) e estágios de desenvolvimento ${ }^{4}$. Para tanto, torna-se necessário definir de forma clara os conceitos de desenvolvimento e territórios urbano e rural.

Os conceitos e medidas de desenvolvimento econômico, ao buscarem representar as condições de vida de países e regiões, têm apresentado, recentemente, novas abordagens teóricas e metodológicas. O caminho que o tema percorre vai da abordagem unidimensional, em que a renda monetária é a variável que determina o nível de desenvolvimento pessoal ou regional, até a abordagem multidimensional que, além da renda, incorpora outras informações socioeconômicas. O Índice de Desenvolvimento da Família (IDF), proposto por Barros et.al. (2003), dentro da perspectiva multidimensional, procura medir o nível de desenvolvimento através de seis dimensões: ausência de vulnerabilidade, acesso ao conhecimento, acesso ao trabalho, disponibilidade de recursos, desenvolvimento infantil e condições habitacionais. $\mathrm{O}$ indicador apresenta duas características importantes. Primeira, ao adotar uma diversidade de aspectos que determinam a capacidade de escolhas dos indivíduos, se aproxima da análise das "capacitações” de Sen (2001), "que considera os relacionamentos existentes numa sociedade como funcionamentos e pressupõe essencial analisar as capacitações dos indivíduos no tocante à participação em tais funcionamentos", os quais podem variar desde coisas elementares como estar nutrido adequadamente até realizações mais complexas, tais como ter respeito próprio, ser feliz e tomar parte na vida da comunidade $^{5}$. A segunda característica é que a família, utilizada como unidade de análise do desenvolvimento humano, representa importante espaço no "conjunto capacitário" e tem papel fundamental, principalmente na sociedade brasileira, na liberdade de escolhas e na possibilidade de acesso a importantes atributos do desenvolvimento humano ${ }^{6}$.

A delimitação dos espaços urbanos e rurais apresenta grande complexidade. Isso decorre, segundo Monte-Mor (1994), do processo de urbanização extensiva, que se intensificou a partir da década de 1980, e que representa,

4 Segundo Rocha \& Santos (2007), em Minas Gerais, ao mesmo tempo em que se observa uma economia baseada na agricultura familiar com altos índices de pobreza e miséria, no Jequitinhonha e Vale do Mucuri têm-se, de outro lado, uma indústria e o setor de serviços dinâmicos na região Metropolitana de Belo Horizonte, agricultura moderna na produção de grãos no Triângulo Mineiro, a pecuária leiteira e a criação de gado de corte na Zona da Mata, a agricultura comercial especializada na fruticultura e floricultura no Campo das Vertentes e, finalmente, uma indústria de tecnologia da informação em processo de consolidação no Sul de Minas

5 A capacidade para realizar funcionamentos depende de um conjunto de fatores, denominado de "conjunto capacitário”, representado por grupos sociais, partido político, organizações não governamentais, grupos religiosos e, também, a família, que reflete, no espaço de funcionamentos, a liberdade dos indivíduos escolherem vidas possíveis.

6 Segundo Medeiros (2000), em economias de mercado, principalmente a de países em desenvolvimento, onde os bens e serviços são obtidos pelos indivíduos primordialmente em função da sua capacidade produtiva, a sobrevivência dos indivíduos que se encontram fora do mercado de trabalho, por questões da estrutura etária, crianças e idosos, ou pela ocorrência de crises e do nível da atividade econômica, dependem de políticas compensatórias. As instituições que amenizam os efeitos deletérios dos mecanismos distributivos do mercado são, primeiramente, o estado, com suas políticas compensatórias e, também, a família através da solidariedade entre os seus membros. 
na verdade, a dominação da lógica urbana sobre o campo, "ficando difícil falar de cidade ou de campo e/ou processos sócio-espaciais antagônicos, na medida em que seus limites, natureza e características estão cada dia mais difusos e integrados"?.

No presente trabalho, optou-se pela delimitação do IBGE, que considera espaço urbano as áreas definidas pela legislação municipal, com as áreas residuais sendo consideradas espaços rurais ${ }^{8}$. As condições de vida e o bem-estar das famílias estão condicionados à realidade socioeconômica e geográfica das regiões em que estão inseridos. Neste sentido, ao analisar as disparidades do desenvolvimento, o trabalho apresenta dois cortes territoriais diretamente relacionados. O primeiro é a delimitação dos espaços urbanos e rurais, onde se procura verificar as condições do desenvolvimento das famílias. O segundo corte, onde se dará essa delimitação, são as sessenta e seis microrregiões do Estado de Minas Gerais.

Em síntese, com o intuito de contribuir com os debates que procuram delimitar os diferentes níveis de relacionamento entre o rural e o urbano, o trabalho, a partir do conceito multidimensional de desenvolvimento, compatível com a análise das "capacitações", apresenta os seguintes objetivos específicos: i) através do cálculo do IDF, composto de seis dimensões, descreve-se as disparidades das condições de vida das famílias nas regiões urbana e rural das sessenta e seis microrregiões mineiras; ii) através da estatística I de Moran, verifica-se a existência da autocorrelação espacial do IDF e de suas seis dimensões; e, finalmente, iii) Através do diagrama de dispersão e dos indicadores locais de associação espacial, verifica-se, nos setores urbano e rural, como o acesso ao trabalho nas microrregiões se relaciona com o acesso ao conhecimento das regiões vizinhas; e, finalmente, a relação entre o IDF urbano nas microrregiões com a diferença percentual entre o IDF urbano e rural de seus vizinhos.

O trabalho é constituído, além da presente introdução, de mais quatro seções. A segunda seção descreve de forma sucinta a metodologia de cálculo do IDF e da Análise Exploratória de Dados Espaciais (AEDE). A terceira seção apresenta os resultados empíricos. E a quarta seção, a título de conclusão, traça alguns comentários.

7 Reforçando essa linha de pensamento, Kageyama (2003) afirma que "as diferenças entre agrícola e rural podem ser bem definidas, onde o primeiro termo refere-se a um setor da atividade econômica, enquanto a noção de rural é territorial e espacial, e em seu interior podem ser desenvolvidas atividades de praticamente todos os setores econômicos".

8 Segundo Del Grossi \& Graziano (2002), a partir de 1991, essa classificação, visando diminuir certo grau de arbitrariedade, passou a utilizar critérios complementares de concentração demográficas e de proximidade a núcleos habitacionais para identificar mais detalhadamente as áreas urbanas e rurais. Desde então, as áreas urbanas são subdivididas em a) urbanizada de vila ou cidade, b) não urbanizada de vila ou cidade e c) urbanizada isolada; e as áreas rurais em: d) extensão urbana, e) povoado, f) núcleo, g) outros aglomerados e, finalmente, h) rural - exclusive os aglomerados rurais. 


\section{Metodologia}

\section{1. Índice de Desenvolvimento da Família (IDF)}

\subsubsection{Composição do IDF}

O IDF, segundo a metodologia desenvolvida por Barros et.al. (2003), é composto por seis dimensões, quais sejam, a) ausência de vulnerabilidade, b) acesso ao conhecimento, c) acesso ao trabalho, d) disponibilidade de recurso, e) desenvolvimento infantil e f) condições habitacionais. "Cada uma dessas dimensões representa, em parte, o acesso aos meios necessários para as famílias satisfazerem suas necessidades e, em outra parte, a consecução de fins, ou seja, a satisfação efetiva de tais necessidades”. O diagrama, descrito na Figura 1, demonstra a inter-relação dessas dimensões, partindo daquelas mais relacionadas ao acesso a meios para concluir com as dimensões mais relacionadas com as consecuções de fins.

As dimensões se desdobram em 24 componentes, constituídos de 43 indicadores socioeconômicos, descritos no Quadro 1. O IDF, a título de exemplo, é calculado como se cada família respondesse sim ou não para cada um dos 43 indicadores. Cada sim é computado como algo positivo e aumenta a pontuação da família na direção de um maior nível de desenvolvimento humano. O IDF, resultante desse questionário, pode variar entre zero (para aquelas famílias na pior situação possível) e um (para as famílias na melhor situação possível). ${ }^{9}$

\section{FIGURA 1 - ESQUEMA DA INTER-RELAÇÃO DAS DIMENSÕES DO IDF}

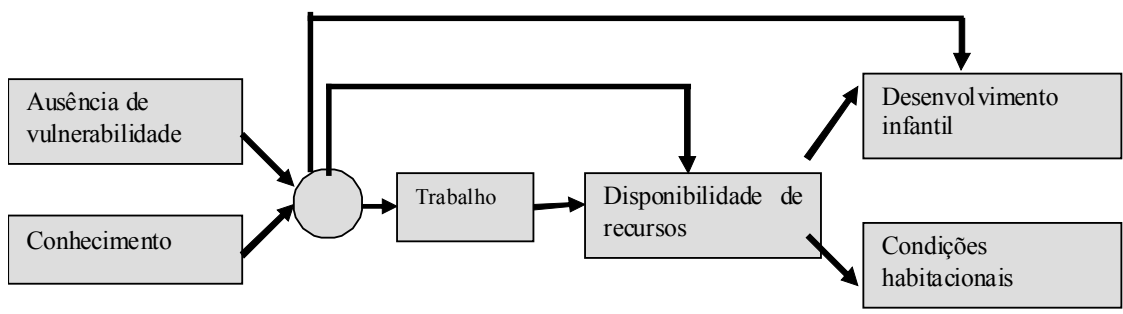

FONTE: Barros et.al. (2003)

9 A escolha dos indicadores que compõem os índices sintéticos e os seus respectivos pesos não se trata de uma questão técnica, mas sim do juízo de valor do pesquisador, que deve refletir, nesta perspectiva, as preferências da sociedade. No presente trabalho, optamos por utilizar a mesma composição do IDF calculado por Barros et al. (2003) porque: (1) os indicadores representam com bastante propriedade as dimensões do nível de vida da família brasileira e (2) permitirá uma análise comparativa do IDF do presente trabalho com o índice calculado pelos autores para as grandes regiões do Brasil. 
O IDF, com suas seis dimensões que se relacionam entre si em meios que viabilizam fins, é compatível com a abordagem das capacitações, mas em uma perspectiva coletiva. A abordagem, desenvolvida em grande parte por Sen (1999), apresenta uma perspectiva individual, e conceitua o bem-estar não como a observação de realizações específicas, mas sim como a capacidade que os indivíduos possuem em escolher entre diferentes realizações. Neste caso, a privação é definida pela falta de oportunidade de escolha e, como consequência, pela impossibilidade de cumprir um plano de vida. E o bemestar é definido como a existência de liberdades substantivas traduzidas nas oportunidades de escolhas. Contudo, a perspectiva individual da abordagem deve levar em conta a influência das condições sociais, na medida em que as pessoas estabelecem um conjunto de relações com vínculos de afeto, poder e cooperação, que determina a amplitude das liberdades de escolha. Se, por um lado, as habilidades e condições pessoais em ser e fazer o que se considera valioso são decisões individuais, de outro, essas condicionantes da escolha individual são construídas socialmente. Neste sentido, as capacitações têm simultaneamente uma dimensão individual e coletiva.

Ao utilizar a família como unidade de análise do desenvolvimento humano, o IDF tem uma perspectiva coletiva da abordagem, assumindo que o convívio dos seus membros, representado pelas seis dimensões do indicador, pode gerar externalidades positivas e negativas que condicionam a liberdade de escolha dos indivíduos e a possibilidade de acesso a importantes atributos do desenvolvimento humano ${ }^{10}$.

Além da compatibilidade com a abordagem das capacitações, deve-se destacar que a metodologia de cálculo do IDF supera uma importante limitação de outros indicadores compostos, entre eles o Índice de Desenvolvimento Humano (IDH), que são estimados para representar o desenvolvimento apenas de áreas geográficas. O IDH do país, por exemplo, não pode ser obtido a partir da agregação das médias dos IDHs dos estados. Essa falta de agregabilidade decorre do fato de os vários indicadores adotados terem bases populacionais distintas e da não linearidade existente na elaboração do índice, principalmente quando se utiliza como parâmetro de disponibilidade de recursos a renda per capita. A metodologia do Índice de Desenvolvimento da Família (IDF) veio sanar essa grave limitação dos índices sintéticos, qual seja, a falta de capacidade de estimar o desenvolvimento ou carência de cada família em particular, permitindo obter o grau de desenvolvimento de qualquer grupo demográfico ${ }^{11}$.

10 Para a melhor compreensão dos fundamentos teóricos e de algumas metodologias para a mensuração de indicadores de desenvolvimento, na perspectiva da abordagem das capacitações, ver Bagolin (2005) e Mattos (2006).

11 Rocha et. al. (2008), através da estimação do Índice de Desenvolvimento da Família (IDF), descrevem o perfil socio econômico das Microrregiões do Estado de Minas Gerais, nos anos de 1991 e 2000. Além da agregação geográfica, o índice foi calculado também para os seguintes grupos demográficos: famílias compostas por crianças, idosos, negros e chefiadas por mulheres. 


\subsubsection{Metodologia para o cálculo do IDF}

O IDF, como já foi dito anteriormente, é um índice que procura sintetizar, em um único número, as informações de 6 dimensões, constituídas por 24 componentes e 43 indicadores sócio-econômicos. Na sua construção, optou-se por tratar todas as dimensões e seus componentes de forma simétrica, mais especificamente atribuindo o mesmo peso: a) a todos os indicadores de cada componente de uma dimensão; b) a todos os componentes de uma dimensão; c) a cada uma das seis dimensões que compõem o IDF. Desta forma, admitindo que cada indicador varie entre o e 1 , o indicador sintético fica definido a partir dos indicadores básicos através da seguinte equação:

$$
S=\left(\frac{1}{6}\right) \cdot \sum_{K}\left(\frac{1}{m_{K}}\right) \cdot \sum_{J}\left(\frac{1}{n_{K}}\right) \cdot \sum_{I} B_{I J K}
$$




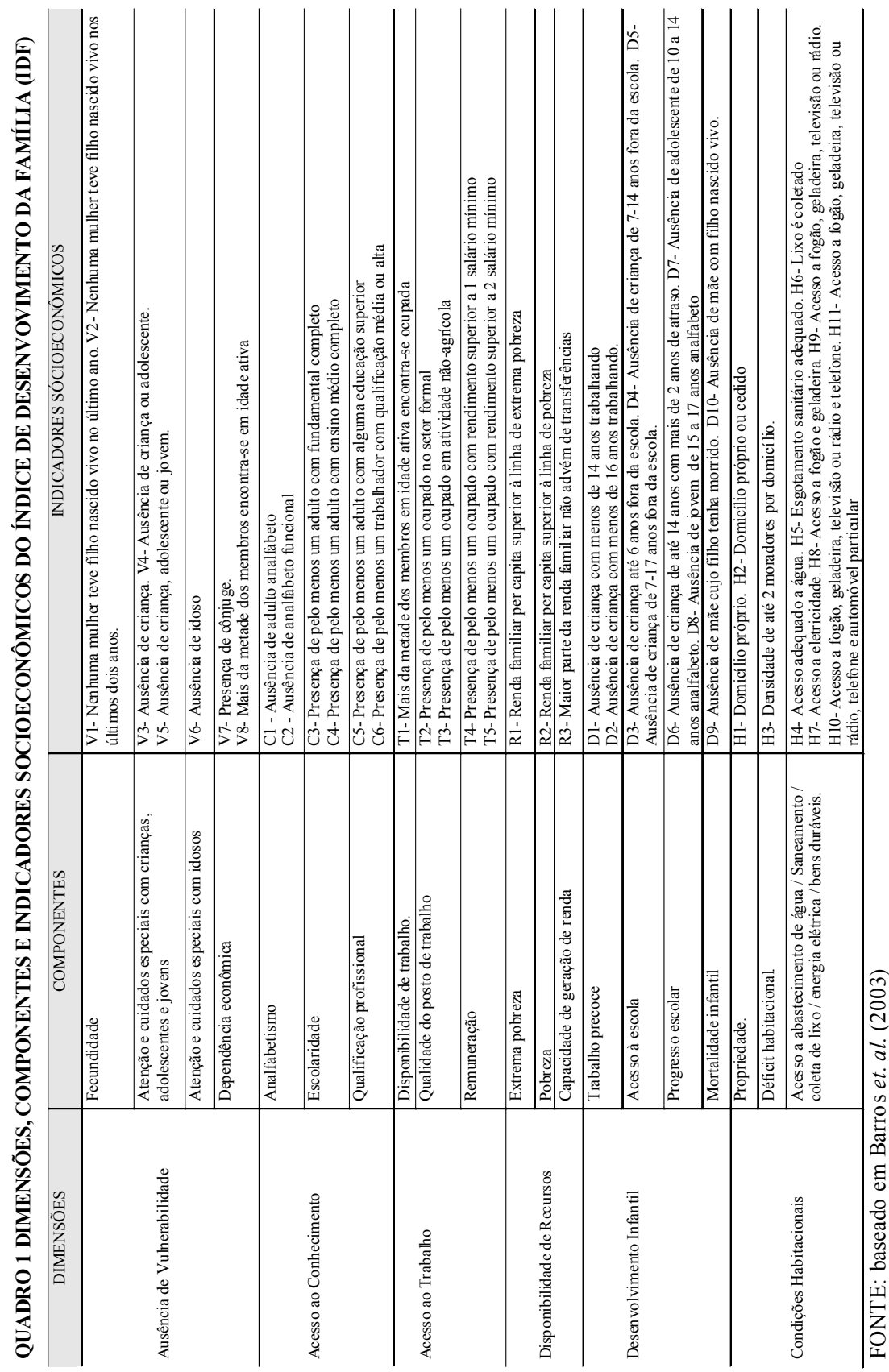


Onde $B_{I J K}$ denota o i-ésimo indicador básico do j-ésimo componente da k-ésima dimensão, $m_{K}$ o número de componentes da k-ésima dimensão, e $n_{K}$ o número de indicadores do j-ésimo componente da k-ésima dimensão. Rearranjando as termos da equação, o indicador pode ser apresentado por:

$$
S=\sum_{K} \sum_{J}\left(\frac{1}{6 . m_{K} \cdot n_{K}}\right) \cdot \sum_{I} B_{I J K}
$$

e, portanto, que:

$$
w_{I J K}=\frac{1}{6 \cdot m_{K} \cdot n_{K}}
$$

A equação acima demonstra que indicadores básicos de componentes distintos terminam, em geral, tendo pesos também distintos, na medida em que o número de indicadores por componentes e o número de componentes por dimensão não são homogêneos. Sendo assim, o peso de um indicador depende do componente e da dimensão a que pertence.

Implicitamente, pode-se obter indicadores sintéticos para cada um dos componentes de cada dimensão, $S_{K}$, assim como para cada uma das dimensões, $S_{K}$, por meio de:

e:

$$
S_{K}=\left(\frac{1}{n_{K}}\right) \cdot \sum_{I} B_{I J K}
$$

$$
S_{K}=\left(\frac{1}{m_{K}}\right) \cdot \sum_{J} S_{K}=\left(\frac{1}{m_{K}}\right) \cdot \sum_{J}\left(\frac{1}{n_{K}}\right) \cdot \sum_{I} B_{I J K}
$$

Observa-se também que:

$$
S=\left(\frac{1}{6}\right) \cdot \sum_{K} S_{K}
$$

Sendo assim, o indicador sintético de cada componente, $S_{K}$, é a média aritmética dos indicadores utilizados para representar esse componente. 
Da mesma forma, o indicador sintético de cada dimensão, $S_{K}$, é a média aritmética dos indicadores sintéticos dos seus componentes. E finalmente, o indicador sintético global, S, é a média aritmética dos indicadores sintéticos das seis dimensões que o compõem.

\subsection{Análise exploratória de dados espaciais}

As análises exploratórias de dados espaciais (AEDE) são úteis para estudar os diversos fenômenos entre regiões, entre eles os socioeconômicos, levando-se em consideração o relacionamento e a distribuição dos dados no espaço. Essas análises, em geral, podem diagnosticar dois efeitos distintos: dependência e heterogeneidade espaciais. A ocorrência da dependência espacial pode se manifestar através da autocorrelação. Quando positiva, na presente pesquisa, indica que as microrregiões que apresentam altos indicadores tanto para o IDF quanto para as dimensões são vizinhas de microrregiões que apresentam também elevados indicadores para essas variáveis; ou, alternativamente, as microrregiões com baixos indicadores são circundados também por regiões que apresentam indicadores pequenos. No caso de autocorrelação negativa observa-se o contrário, ou seja, microrregiões com altos indicadores com vizinhos com baixo ou, alternativamente, microrregiões com baixos indicadores vizinhos de municípios com altos indicadores.

Para verificar a ocorrência da dependência torna-se necessário definir a matriz de pesos espaciais (W) que expressa a estrutura espacial dos dados. $\mathrm{Na}$ presente pesquisa, a matriz de peso espacial W será construída utilizando a ideia de contiguidade, onde duas regiões são consideradas vizinhas quando compartilham uma fronteira física comum. Na matriz, quando a região i for vizinha da j, ambas recebem a notação unitária, e caso não haja relação de vizinhança, atribui-se o valor zero. Essa relação pode ser representada da seguinte forma:

$w_{\ddot{j}}=1$ se i e $\mathrm{j}$ são contíguos

$w_{i j}=$ o se i e j não são contíguos

Agora deve-se definir o que se entende por contiguidade. Dentre várias possibilidades, no presente trabalho optou-se pela convenção rainha, que considera como área contígua, além das fronteiras com extensão diferente de zero, os vértices ou esquinas do mapa, e o nível contiguidade de segunda ordem, ou seja, a matriz é composta dos vizinhos dos vizinhos da região de interesse ${ }^{12}$.

12 Segundo Haddad \& Pimentel (2004), entre os diversos métodos para construir a matriz de pesos espaciais, os mais utilizados são o Rainha (Queen) e o Torre (Rook). A matriz Rainha é mais robusta e considera vizinhas duas regiões que apresentem fronteiras comuns, além de nós comuns (vértices). A matriz Torre por definição é mais simples, considerando vizinhas apenas as regiões que possuam uma fronteira comum. 
Ao proceder a AEDE é recomendável o uso de variáveis espacialmente densas, ou seja, que são divididas por algum indicador de quantidade. Isso porque variáveis absolutas tendem a estar correlacionadas com a área ou população da região, resultando em análises viesadas (Anselin 2003). As variáveis a serem analisadas na presente pesquisa são densas, pois o IDF e as suas dimensões tratam de indicadores relativos ao número de famílias por microrregião. Segundo Gonçalves (2005), "métodos convencionais, como regressões múltiplas e inspeção visual de mapas, não são formas mais adequadas de lidar com dados georeferenciados, pois não são confiáveis para detectar agrupamentos e padrões espaciais significativos". Sendo assim, em vez da análise "superficial", o mais indicado é obter as medidas de autocorrelação espacial global e local. Para se obter essas medidas utilizam-se o método I de Moran univariado e também sua versão multivariada. Para se obter as medidas de autocorrelação espacial local (LISA) utilizam-se o diagrama de dispersão de Moran e o mapa de Cluster em suas versões univariada e multivariada. Esses métodos serão descritos a seguir.

\subsubsection{Autocorrelação espacial global univariada e multi- variada}

Através da estatística I de Moran se verifica a existência ou não da autocorrelação espacial. Essa estatística formaliza o grau de associação linear entre os vetores de valores observados no tempo $t\left(z_{t}\right)$ e a média ponderada dos valores da vizinhança $\left(\mathrm{WZ}_{\mathrm{t}}\right)$. Valor de I de Moran maiores (ou menores) do que o valor esperado $E(I)=-1 /(n-1)$ significa que há correlação positiva (ou negativa). Sendo que n é o número de unidades espaciais. Segundo Cliff \& Ord (1981), quando a matriz de pesos espaciais é normalizada na linha, ou seja, quando os elementos de cada linha somam 1, a formalização da estatística I de Moran univariada pode ser expressa da seguinte forma:

$$
I_{t}=\left(\frac{Z_{t}^{\prime} W Z_{t}}{Z_{t}^{\prime} Z_{t}}\right) \quad \mathrm{t}=\{1,2 \ldots \mathrm{n}\}
$$

onde $Z t$ é o vetor de $n$ observações para o ano $t$ na forma de desvio em relação à média. $W Z_{t}$ é a matriz quadrada $\operatorname{com} n^{2}$ elementos, na qual, como já foi descrito, cada elemento, $w_{i j}$ representa uma medida de proximidade espacial entre a região $i$ e a região $j$. Segundo essa formulação, a estatístiva I de Moran é a relação da autocovariância do tipo-produto cruzado $\left(Z^{\prime} W Z_{t}\right)$ pela variância dos dados $\left(Z^{\prime} Z_{t}\right)$.

Os valores da estatística de I de Moran variam entre - 1 e 1, onde -1 representa um coeficiente de correlação linear perfeitamente negativo enquanto o valor positivo consiste em um coeficiente linear perfeitamente positivo.

Para verificar a existência de autocorrelação entre uma dada variável observada em uma região e uma outra variável em uma região vizinha, deve-se 
utilizar o I de Moran global multivariado. Segundo Almeida (2007), o coeficiente do I de Moran global multivariado, com a matriz W já normalizada na linha, para duas variáveis diferentes padronizadas, $z_{k}$ e $z_{l}$, é representado pela seguinte equação:

$$
I_{k, l}=\frac{Z_{k}^{\prime} W_{l}}{Z_{k}^{\prime} Z_{k}}
$$

A estatística $I$ de Moran, por ser uma medida de associação espacial global, não é capaz de revelar padrões de associação espacial local. Para analisar os padrões de associação local há duas metodologias: o diagrama de dispersão de Moran e os Indicadores Locais de Associação Espacial (Local Indicators of Spatial Association - LISA)

\subsubsection{Diagrama de dispersão de Moran}

O diagrama de dispersão de Moran univariado é o coeficiente de regressão linear de Wz em relação a z representado em um gráfico, onde a coeficiente da curva de regressão é a estatística I de Moran. O diagrama de dispersão é dividido em quatro quadrantes que correspondem às associações espaciais locais de determinada região em relação aos seus vizinhos. Segundo Almeida (2007), os quatro quadrantes são representados da seguinte forma:

i) Alto-Alto (AA), que localiza-se na parte superior direita do gráfico e representa microrregiões que possuem valores acima da média para uma determinada variável cercados por microrregiões que também possuam valores acima da média para esta variável.

ii) Baixo-Alto (BA), que localiza-se na parte superior esquerda do gráfico e representa as microrregiões com baixos valores para a variável de interesse, rodeados por microrregiões que possuem elevado valor para essa mesma variável.

iii) Baixo-Baixo (BB), que localiza-se na parte inferior esquerda do gráfico e indica microrregiões que possuem baixos valores para a variável em análise, cercadas por microrregiões de também baixo valor para a mesma variável.

iv) Alto-Baixo $(\mathrm{AB})$, localizado na parte inferior direita do gráfico representa as microrregiões que possuem valores acima da média para a variável de interesse, circundadas por microrregiões que possuem valores abaixo da média para a mesma variável.

As microrregiões AA e BB apresentam padrões de associação espacial positivo, formando cluster de valores similares, enquanto as microrregiões $\mathrm{AB}$ e BA apresentam associação espacial negativa, formando cluster de valores distintos. 
O diagrama de dispersão de Moran multivariado, que demonstra a associação espacial de duas variáveis diferentes, no caso $z_{k}$ e $z_{l}$, segue o mesmo padrão de análise do diagrama de dispersão de Moran univariado, sendo que o eixo das ordenadas é representado por $W l$, que é a variável $l$ defasada para os vizinhos confrontada com a variável $k$ no eixo das abscissas.

\subsubsection{Indicadores Locais de Associação Espacial (LISA)}

Um "Local Indicators of Spatial Association (LISA)" trata-se de qualquer estatística que satisfaça a dois critérios: a) um indicador LISA deve ter, para cada observação, uma indicação de Clusters espaciais significantes de valores similares em torno da observação (regiões); b) o somatório dos indicadores LISA, para todas as regiões, deve ser proporcional ao indicador de autocorrelação espacial global (Anselin 1995). Os indicadores LISA, conforme Le Gallo \& Erthur (2003), quando baseados no I de Moran local, podem ser representados pela seguinte equação:

$$
I_{i, t}=\frac{\left(x_{i, t}-\mathrm{m}\right)}{m_{0}} \sum_{j} w_{i, j}\left(x_{i, t}-\mathrm{m}\right) \operatorname{com} m_{0}=\frac{\left(x_{i, t}-\mathrm{m}\right)^{2}}{n}
$$

onde $x i, t$ é a observação de uma variável de interesse na região $i$ para o ano $t, \mu t$ é a média das observações entre todas as regiões para o ano $t$, no qual, o somatório em relação a $j$ é tal que somente os valores vizinhos de $j$ são incluídos.

A estatística LISA permite medir a hipótese nula da ausência de associação espacial local. Para tanto, deve-se fazer uso de uma aleatorização condicional, que permite determinar pseudoníveis de significância estatística. Segundo Cliff \& Ord (1981), para obter-se uma distribuição empírica das estatísticas de teste, deve-se observar se o valor da variável de interesse está dentro ou fora da região crítica definida. Neste caso, se o valor calculado for superior à esperança matemática do I de Moran, seus resultados serão estatisticamente significativos.

\subsection{Fonte de dados}

Os 43 indicadores socioeconômicos, descritos no Quadro 1, que compõem IDF, foram obtidos no Instituto Brasileiro de Geografia e Estatística (IBGE), extraídos do Censo demográfico 2000. Na medida em que o Censo não disponibiliza em seus resultados finais as informações dos indicadores para cada família em separado, tornou-se necessário, para tanto, acessar os microdados da amostra. 


\section{Análise empírica}

\subsection{Distribuição das famílias}

A partir da amostra do Censo Demográfico de 2000, foi possível analisar a base de dados de 650.625 famílias no Estado de Minas Gerais, as quais, com a utilização do fator de expansão ${ }^{13}$, representam o universo de 5.099.966 famílias. Sendo que deste total, 4.264.515, ou seja, $84 \%$ das famílias residem nas áreas urbanas e os restantes $16 \%$, ou seja, 832.450 famílias,nas áreas rurais. ${ }^{14}$

A distribuição populacional das famílias do Estado de Minas Gerais, em 2000, descrita na Tabela 1, demonstra que em todas as mesorregiões, como era de esperar, verifica-se o predomínio das famílias urbanas ${ }^{15}$. As maiores participações das famílias rurais no total da população encontram-se no Vale do Jequitinhonha, com quase 40\%, seguida do Norte de Minas e Vale do Mucuri com 33\% e da mesorregião Noroeste de Minas com 25\%. As regiões predominantemente urbanas são: Metropolitana de Belo Horizonte com 94\% das famílias residindo em domicílios urbanos, o Triângulo Mineiro com quase 90\% e o Oeste de Minas com 85\%. Somando-se a população total, essas três mesorregiões compreendem quase a metade das famílias do estado.

TABELA 1. DISTRIBUIÇÃO DAS FAMÍLIAS ENTRE AS MESORREGIÕES DE MINAS GERAIS, 2000

\begin{tabular}{cccccc}
\hline Mesorregiões & $\begin{array}{c}\text { Famílias } \\
\text { urbanas }\end{array}$ & $\begin{array}{c}\text { Famílias } \\
\text { rurais }\end{array}$ & Total & $\begin{array}{c}\text { \% Famílias } \\
\text { urbanas }\end{array}$ & $\begin{array}{c}\text { \% Famílias } \\
\text { rurais }\end{array}$ \\
\hline Noroeste & 70243 & 23300 & 93543 & 75,09 & 24,91 \\
Norte & 252236 & 122597 & 374833 & 67,29 & 32,71 \\
Jequitinhonha & 103273 & 68283 & 171556 & 60,20 & 39,80 \\
Vale do Mucuri & 69085 & 33329 & 102415 & 67,46 & 32,54 \\
Triângulo & 511622 & 61233 & 572855 & 89,31 & 10,69 \\
Central Mineira & 94664 & 16972 & 111636 & 84,80 & 15,20 \\
Metropolitana BH & 1506611 & 90276 & 1596887 & 94,35 & 5,65 \\
Vale do Rio Doce & 331852 & 93735 & 425587 & 77,98 & 22,02 \\
Oeste & 211168 & 36240 & 247407 & 85,35 & 14,65 \\
Sul Sudoeste & 518650 & 139811 & 658461 & 78,77 & 21,23 \\
Vertentes & 123121 & 26170 & 149291 & 82,47 & 17,53 \\
Zona da Mata & 471991 & 123504 & 595495 & 79,26 & 20,74 \\
Minas Gerais & 4264515 & 835450 & 5099966 & 83,62 & 16,38 \\
\hline
\end{tabular}

FONTE: elaboração dps autores a partir dos dados da pesquisa.

13 Refere-se ao valor da ponderação ou fator de expansão fornecido pelo IBGE associado a cada unidade amostral, para obtenção de estimativas do universo. Informações sobre o cálculo poderão ser encontradas no manual do censo demográfico de 2000.

14 A família, segundo definição do Censo Demográfico do IBGE (200o), é o conjunto de pessoas ligadas por laços de parentesco, dependência doméstica ou normas de convivência, que reside na mesma unidade domiciliar e, também, a pessoa que mora sozinha em uma unidade domiciliar.

15 A distribuição das famílias para as microrregiões do Estado apresenta também o predomínio urbano, com exceção para as seguintes regiões: Araçuaí e Capelinha (Jequitinhonha), ambas com 55\% de famílias rurais; Conceição do Mato Dentro, 52\%, e Itaguara, 50\% (Metropolitana de Belo Horizonte); Grão Mogol, 60\%, Januária e Salinas, 50\% (Norte de Minas) e, finalmente, Peçanha, 60\% (Vale do Rio Doce). A Figura A1, anexo do trabalho, descreve a composição das mesorregiões e a localização das microrregiões no mapa do Estado de Minas Gerais. 


\subsection{IDF rural e urbano do Estado de Minas Gerais}

O índice de desenvolvimento da família (IDF), que varia entre zero e um, alcançou, para o Estado de Minas Gerais, a magnitude de o,64. As famílias que residem em domicílios urbanos apresentaram índice ligeiramente superior ao do estado, o,66, enquanto que para as famílias do meio rural o IDF foi consideravelmente inferior, apenas 0,50. Esses indicadores descrevem de forma sintética as condições de vidas das famílias mineiras. Uma forma alternativa de comparar as condições de vida das regiões rural e urbana é apresentar as seis dimensões desses indicadores em um biograma, gráfico que demonstra o estado de um sistema em um determinado ponto no tempo. A representação gráfica facilita a visualização das diferentes dinâmicas de desenvolvimento das regiões, seus aparentes desequilíbrios e possíveis conflitos existentes entre as dimensões. Os Biogramas são "gráficos de radar" nos quais cada dimensão é representada num eixo próprio, todos irradiando a partir do ponto central ${ }^{16}$. A representação gráfica do biograma do IDF das regiões urbana e rural do Estado de Minas Gerais para o ano de 2000, caracterizada na Figura 2, demonstra um desequilíbrio entre as seis dimensões para ambas as regiões.

Para o setor urbano, o hexagrama se aproxima mais da borda para as dimensões Condições Habitacionais (CH), Desenvolvimento Infantil (DI) e Disponibilidade de Renda (DR), caracterizadas no diagrama da Figura 1 como os fins do desenvolvimento, enquanto as variáveis que representam os meios, Ausência de Vulnerabilidade (AV), e principalmente as dimensões Acesso ao Conhecimento (AC) e Acesso ao Trabalho (AT), aproximam-se da origem, demonstrando um baixo desenvolvimento para essas dimensões. Para o setor rural, as dimensões Ausência de Vulnerabilidade (AV) e Desenvolvimento Infantil (DI) igualam-se aos níveis observados para o setor urbano, com as demais dimensões apresentando condições nitidamente mais desfavoráveis, com destaque, também, para o Acesso ao Conhecimento (AC) e o Acesso ao Trabalho (AT).

16 É importante ressaltar que as imagens resultantes da operacionalização do Biograma são sensíveis à ordenação das dimensões. Neste caso, para que a comparação dos resultados possa fazer sentido, todas as imagens devem ser construídas com as mesmas dimensões e na mesma ordem. 
FIGURA 2. BIOGRAMA DO IDF DAS REGIÕES URBANA E RURAL DO ESTADO DE MINAS GERAIS, 2000

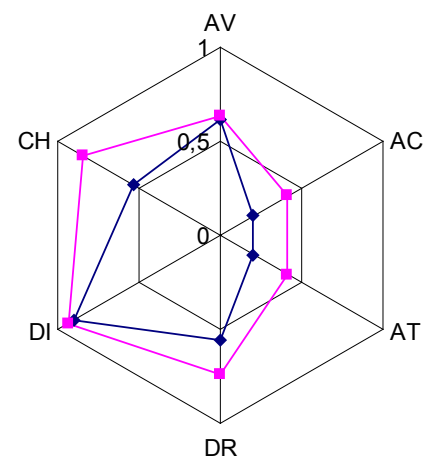

FONTE: elaboração própria a partir dos dados da pesquisa.

As dimensões do IDF, descritas no biograma, referem-se à situação média do Estado, resta saber as suas características territoriais. Essa análise será feita para as microrregiões do Estado a seguir. Entretanto, a Tabela 2 descreve algumas estatísticas básicas, tais como os índices mínimos, máximos, média e desvio padrão para as regiões rural e urbana, permitindo verificar as suas disparidades.

TABELA 2. ESTATÍSTICAS BÁSICAS DO IDF E DE SUAS DIMENSÕES

\begin{tabular}{|c|c|c|c|c|c|}
\hline Dimensão & Região & Mínimo & Máximo & Média & $\begin{array}{c}\text { Des. } \\
\text { Padrão }\end{array}$ \\
\hline \multirow[t]{2}{*}{ Ausência de Vulnerabilidade } & Rural & 0,57 & 0,69 & 0,63 & 0,030 \\
\hline & Urbano & 0.56 & 0.66 & 0.62 & 0.024 \\
\hline \multirow[t]{2}{*}{ Acesso ao Conhecimento } & Rural & 0,16 & 0,28 & 0,21 & 0,025 \\
\hline & Urbano & 0.28 & 0.46 & 0,36 & 0,044 \\
\hline \multirow[t]{2}{*}{ Condições Habitacionais } & Rural & 0,39 & 0,65 & 0,54 & 0,071 \\
\hline & Urbano & 0,65 & 0.89 & 0.82 & 0.063 \\
\hline \multirow[t]{2}{*}{ Desenvolvimento Infantil } & Rural & 0,86 & 0,94 & 0,90 & 0,021 \\
\hline & Urbano & 0,90 & 0,95 & 0.93 & 0.015 \\
\hline \multirow[t]{2}{*}{ Acesso ao Trabalho } & Rural & 0,09 & 0,36 & 0,21 & 0,077 \\
\hline & Urbano & 0.20 & 0.50 & 0.36 & 0.071 \\
\hline \multirow[t]{2}{*}{ Disponibilidade de Recursos } & Rural & 0,34 & 0,78 & 0,58 & 0,131 \\
\hline & Urbano & 0.48 & 0.85 & 0.70 & 0.089 \\
\hline \multirow[t]{2}{*}{ IDF } & Rural & 0,41 & 0,59 & 0,51 & 0,056 \\
\hline & Urbano & 0.52 & 0.71 & 0.63 & 0.048 \\
\hline
\end{tabular}

FONTE: elaboração própria a partir dos dados da pesquisa. 
As dimensões Ausência de Vulnerabilidade (AV) e Desenvolvimento Infantil (DI) apresentaram comportamento semelhante entre as regiões rural e urbana. Os índices máximos e mínimos tiveram valores próximos, com pequena dispersão dos indicadores em relação à média do estado. Isso demonstra que a estrutura demográfica e a composição das famílias, representadas pelos componentes fecundidade, atenção e cuidados especiais com crianças, adolescentes, jovens e idosos, e dependência, que compõem a dimensão Ausência de Vulnerabilidade, têm características semelhantes para as regiões rural e urbana. A dimensão Desenvolvimento Infantil, formada pelos componentes trabalho precoce, acesso à escola, progresso escolar e mortalidade infantil, também apresenta boas condições em todo o estado, levando em consideração que o indicador mínimo foi de 0,86 . Isso de deve, em grande parte, às políticas públicas, tanto dos órgãos federais quanto estaduais e municipais, voltadas para a proteção à criança.

As dimensões Condições Habitacionais $(\mathrm{CH})$ e Disponibilidade de Recursos (DR), com valores máximos, mínimos e médios discrepantes, em favor do setor urbano, e com alto desvio padrão, demonstram que as condições de vidas das famílias, nesses aspectos, são bastante desiguais entre as regiões rural e urbana e, também, entre as microrregiões do estado. Dentro desta mesma realidade, as dimensões Acesso ao Conhecimento (AC) e Acesso ao Trabalho (AT), apresentaram baixos indicadores para ambas as regiões, sendo que as condições do setor urbano superam consideravelmente as do rural, e alto desvio padrão, que demonstra grande diferença dos indicadores entre as microrregiões do estado. Esse resultado, explicitado também no biograma acima, demonstra que as famílias mineiras, principalmente as localizadas no setor rural, não têm autonomia, através do conhecimento e do trabalho, considerados como meios para obter os fins materiais do desenvolvimento, dependendo, em parte, de políticas públicas compensatórias. Não se pode esquecer também, como já foi descrito anteriormente, que essas dimensões, além dos retornos materiais, possibilitam a ampliação das possibilidades de escolhas genuínas, o aumento da autoestima e, entre outros ganhos, a melhora na participação e envolvimento social.

O propósito da pesquisa é desagregar o indicador para as microrregiões, subdividindo-o para as áreas urbanas e rurais, demonstrando a heterogeneidade das condições de vida das famílias mineiras. A Figura 3 descreve os indicadores do IDF das famílias urbanas para as microrregiões do estado. O índice varia entre 0,52 e 0,71, demonstrando uma clara dualidade nas condições de vida das famílias urbanas. As microrregiões localizadas no Nordeste, Norte, Jequitinhonha e Vale do Mucuri apresentam os menores indicadores, entre 0,52 e 0,62, enquanto as localizadas no Sul, Triângulo, Sudoeste e Central têm os maiores indicadores, variando entre 0,63 e 0,71. As microrregiões que se destacam com os melhores indicadores de bem estar das famílias urbanas são: Uberaba, Uberlândia, Poços de Caldas, Pouso Alegre, Divinópolis, Belo Horizonte e Juiz de Fora. 


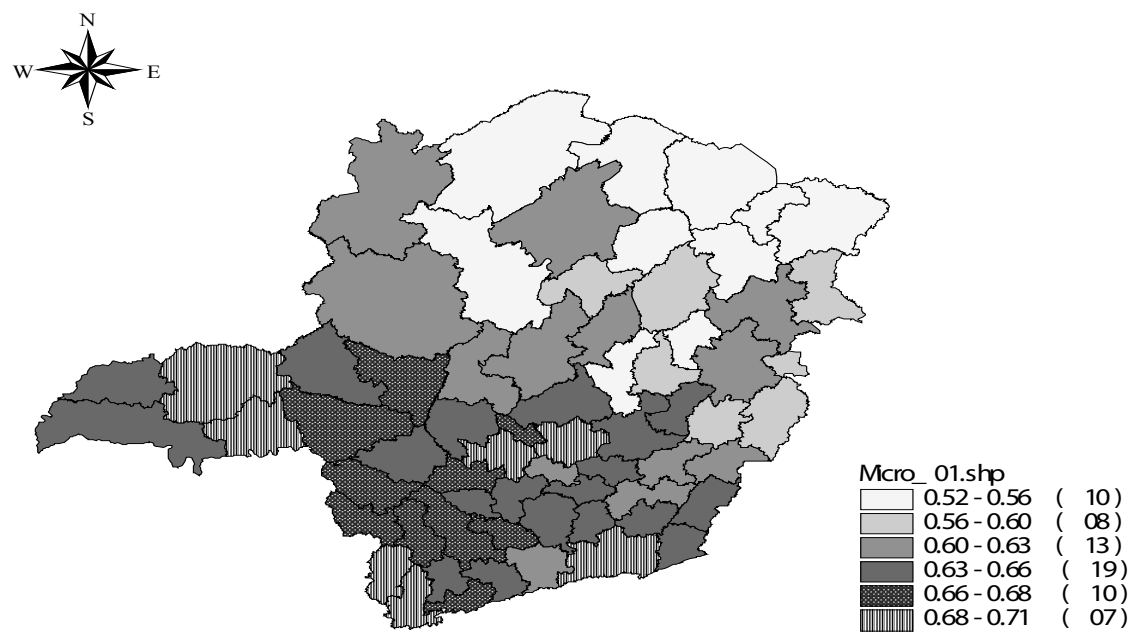

FONTE: elaboração própria a partir dos dados da pesquisa.

A Figura 4, por outro lado, descreve os indicadores do IDF das famílias rurais, que variam entre 0,41 a 0,59, apresentando, como era de se esperar, condições de vida menos favoráveis que o setor urbano. É interessante notar que a mesma dualidade observada para as regiões urbanas do estado, com melhores indicadores no sul em contraposição aos da região norte, ocorre também para o meio rural, porém de forma mais intensa. Dos seis estratos do IDF apresentados no gráfico, quatorze microrregiões se encontram no de menor valor, entre 0,41 e 0,45, todas localizadas nas regiões Norte, Jequitinhonha e Vale do Mucuri. No estrato de maior valor, que varia entre 0,56 e 0,59, encontram-se dezessete microrregiões, concentradas no Triângulo Mineiro, Oeste de Minas, Central Mineira e parte nas regiões Sul e Metropolitana.

Segundo os objetivos do trabalho, torna-se importante verificar a diferença do índice das famílias urbana e rural dentro de cada microrregião do estado. A Figura 5 demonstra, em termos percentuais, essa diferença. A maior discrepância entre as condições de vida das famílias residentes no meio urbano em relação às famílias rurais ocorre justamente nas microrregiões localizadas no Nordeste, Norte, Jequitinhonha e Vale do Mucuri, as quais apresentam os menores níveis de IDF urbano. Esse comportamento ocorre também na Zona da Mata. 
FIGURA 4. DIVISÃO DAS MICRORREGIÕES DO ESTADO DE MINAS GERAIS POR ESTRATOS DO IDF RURAL, 2000
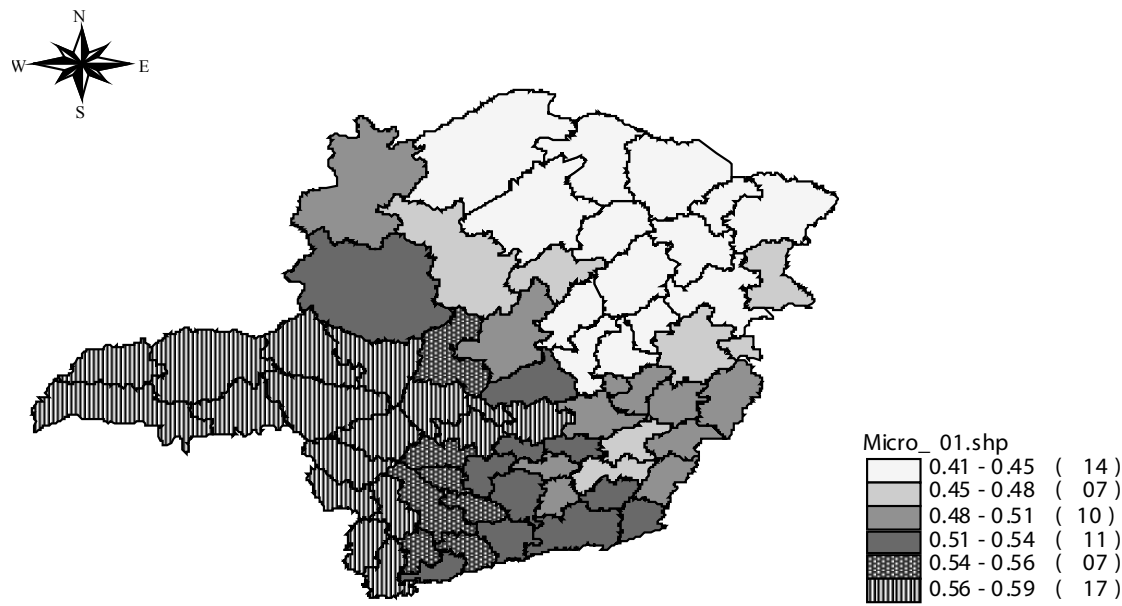

FONTE: elaboração própria a partir dos dados da pesquisa

As microrregiões de Montes Claros, Diamantina, Teófilo Otoni e Viçosa, apresentaram as maiores diferenças, entre 34\% e 41\%. No outro extremo, as microrregiões de maior desenvolvimento urbano, localizadas nas regiões Sul, Triângulo, Sudoeste e Central, apresentaram os menores diferenciais de condições de vida. Esse comportamento demonstra que, de certa forma, o processo de urbanização-extensiva, caracterizado, segundo Monte-Mor (1994), "pela vigência da vida urbana e dos meios de reprodução industrial além dos limites urbanos, incorporando áreas rurais e conectando pequenas cidades aos centros urbano-industriais", ocorre, em Minas Gerais, de forma distinta entre as regiões do estado. Esse processo é mais intenso no sul do estado, enquanto no Norte e na Zona da Mata se verifica uma grande diferença entre as condições de vida das famílias urbanas e rurais.

O IDF, como foi descrito na metodologia, é composto por seis dimensões. Sendo que a i) ausência de vulnerabilidade ( $A V)$, o ii) acesso ao conhecimento $(A C)$ e o iii) acesso ao trabalho (AT), representam, em parte, os meios necessários para as famílias satisfazerem suas necessidades e, por outro lado, as dimensões iv) disponibilidade de recurso (DR), v) desenvolvimento infantil (DI) e vi) condições habitacionais $(\mathrm{CH})$ a consecução de fins, ou seja, a satisfação efetiva de tais necessidades". Cabe ressaltar que, dentro da perspectiva da abordagem das capacitações, as dimensões meios, além de possibilitarem a satisfação de importantes atributos do desenvolvimento, têm importância por si mesmas. O acesso ao conhecimento e ao trabalho, é claro, possibilita ganhos materiais efetivos em uma economia de mercado, mas o retorno vai 
além disso. Através da educação e do emprego os indivíduos ampliam as possibilidades de escolhas genuínas, aumentam a autoestima e, entre outros ganhos, podem melhorar a fluência no campo social ${ }^{17}$.

FIGURA 5. DIVISÃO DAS MICRORREGIÕES DO ESTADO DE MINAS GERAIS POR ESTRATOS DA DIFERENÇA PERCENTUAL ENTRE OS ÍNDICES DE DESENVOLVIMENTO DAS FAMÍLIAS URBANA E RURAL, 2000
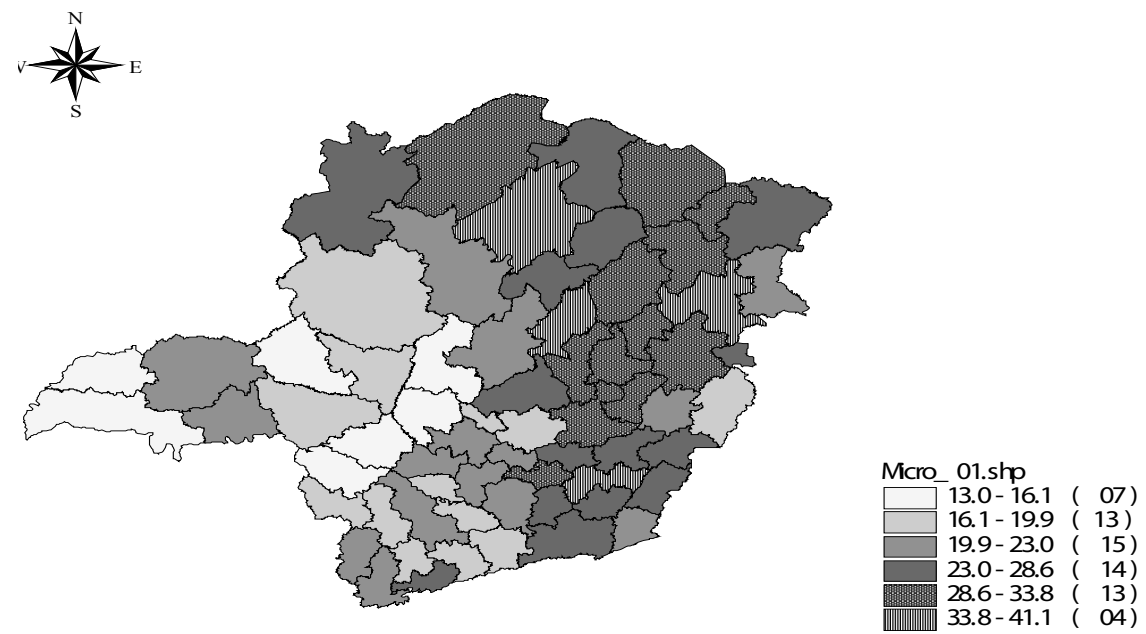

FONTE: elaboração própria a partir dos dados da pesquisa

Até aqui, através da observação visual dos gráficos, do biograma e da tabela com informações estatísticas, foi feita uma análise comparativa do nível do bem estar das famílias rurais e urbanas para as sessenta e seis microrregiões do estado no ano de 2000. Entretanto, essa inspeção visual de mapas não é a forma mais adequada de lidar com dados georeferenciados, pois não possibilita detectar, com confiabilidade, agrupamentos e padrões espaciais significativos. No próximo tópico, para complementar o estudo, será realizado a Análise Exploratória de Dados Espaciais, descrita na metodologia. 


\subsection{Análise da estrutura espacial do IDF e de suas di- mensões}

As análises exploratórias de dados espaciais (AEDE) são úteis para estudar os diversos fenômenos entre regiões, entre eles os socioeconômicos, levando-se em consideração o relacionamento e a distribuição dos dados no espaço. A forma mais simples e intuitiva de análise exploratória foi realizada no tópico anterior, através da visualização dos estratos do IDF das microrregiões no mapa de Minas Gerais. Outra possibilidade mais adequada de se analisar a estrutura espacial é a estatística I de Moran, que será utilizada para verificar a existência ou não da autocorrelação espacial do IDF e de suas dimensões para as famílias rurais e urbanas das sessenta e seis microrregiões do estado. Para analisar os padrões de associação local serão utilizadas duas metodologias: o diagrama de dispersão de Moran e os indicadores locais de associação espacial (Local Indicators of Spatial Association - LISA).

\subsubsection{Autocorrelação espacial global univariada e multi- variada}

Os coeficientes univariados, descritos na Tabela 3, apresentaram validade estatística na medida em que o I de Moran calculado foi superior ao esperado e rejeitou-se a hipótese de ausência de autocorrelação em um nível de significância superior a 0,001\%. O IDF, por exemplo, com I de Moran de 0,86 para a região rural e 0,72 para a urbana, apresenta alta correlação positiva, demonstrando que as regiões com alto IDF tendem a se agrupar em uma mesma localidade, o mesmo ocorrendo com as regiões de baixo IDF.

As dimensões do IDF, com exceção do Acesso ao Conhecimento para a região urbana com coeficiente de apenas 0,35 , apresentaram também alta correlação positiva, assumido valores superiores a 0,65 . A região rural apresentou para o IDF e todas as suas dimensões, com exceção da Ausência de Vulnerabilidade com coeficientes iguais para ambas as regiões, correlação positiva superior ao do setor urbano. Isso demonstra que, principalmente para a região rural, as condições de vida das famílias representadas pelas seis dimensões do IDF, têm um padrão espacial global que se divide em dois grupos: as localidades formadas por microrregiões vizinhas com alto padrão de vida e, em contraposição, as localidades formadas por microrregiões com baixos indicadores de desenvolvimento humano. 
TABELA 3. COEFICIENTES I DE MORAN UNIVARIADO DO IDF E DE SUAS RESPECTIVAS DIMENSÕES

\begin{tabular}{l|l|c}
\hline \multicolumn{1}{c}{ Dimensão } & \multicolumn{1}{c}{ Região } & I de Moran \\
\hline \multirow{2}{*}{ Ausência de Vulnerabilidade } & Rural & 0,7590 \\
\cline { 2 - 3 } & Urbano & 0,7510 \\
\hline \multirow{2}{*}{ Acesso ao Conhecimento } & Rural & 0,6569 \\
\cline { 2 - 3 } & Urbano & 0,3482 \\
\hline \multirow{2}{*}{ Condições Habitacionais } & Rural & 0,8052 \\
\cline { 2 - 3 } & Urbano & 0,7317 \\
\hline \multirow{2}{*}{ Desenvolvimento Infantil } & Rural & 0,8065 \\
\cline { 2 - 3 } & Urbano & 0,7362 \\
\hline \multirow{2}{*}{ Acesso ao Trabalho } & Rural & 0,7871 \\
\cline { 2 - 3 } & Urbano & 0,6482 \\
\hline \multirow{2}{*}{ Disponibilidade de Recursos } & Rural & 0,8631 \\
\cline { 2 - 3 } & Urbano & 0,7758 \\
\hline \multirow{2}{*}{ IDF } & Rural & 0,8644 \\
\cline { 2 - 3 } & Urbano & 0,7244 \\
\hline
\end{tabular}

FONTE: elaboração própria a partir dos dados da pesquisa. Todos os coeficientes apresentaram significância estatística superior a 0,001\%, obtida através de 999 permutações aleatórias.

A autocorrelação global multivariada, em um contexto bivariado demonstra a relação que uma variável observada em uma região tem com outra variável em regiões vizinhas. Neste sentido, as análises da Tabela 4 permitem verificar a interação espacial das áreas urbanas com as regiões rurais em seu entorno. A primeira variável, IDF(U/R), com correlação positiva de 0,78 , demonstra que os setores urbanos das microrregiões com alto IDF são vizinhos de regiões rurais com altos indicadores de IDF e, também, as regiões urbanas com baixo IDF são circundadas por regiões rurais de baixo IDF. Complementando essa análise, a variável, IDF(U)/percentual IDF(U/R), que apresentou correlação negativa de - 0,60, demonstra a relação do IDF urbano com as disparidades das condições de vida, medidas pela diferença percentural do IDF urbano e rural, nas microrregiões vizinhas. Neste sentido, as regiões urbanas com alto IDF são vizinhas de regiões com baixa disparidade entre o IDF do setor urbano e rural e, por sua vez, as regiões de baixo IDF são circundadas por regiões com grande diferença entre o IDF urbano e rural. Essas correlações bivariadas demonstram que nas regiões mais desenvolvidas, portanto, há uma tendência de convergência das condições de vidas entre o urbano e o rural, enquanto que nas regiões com baixo desenvolvimento verifica-se justamente o contrário, ou seja, o aumento das diferenças das condições socioeconômicas da região urbana em relação às regiões rurais.

A terceira variável busca verificar empiricamente a inter-relação, descrita na Figura 1, da dimensão Acesso ao Conhecimento das famílias ao Acesso 
ao Trabalho. A influência da educação no desenvolvimento econômico é amplamente abordada pela Teoria do Capital Humano e, também, pela Abordagem das Capacitações. Neste sentido, buscou-se, tanto para o setor urbano quanto rural, verificar a relação espacial entre essas duas dimensões. Os coeficientes para as regiões rural e urbana foram, respectivamente, de o,69 e 0,47, demonstrando que as regiões com alto Acesso ao Trabalho são cercadas por regiões com altos indicadores de Acesso ao Conhecimento e, por sua vez, as regiões com baixo Acesso ao Trabalho são circundadas por regiões com pouco Acesso ao Conhecimento. Essa correlação positiva, mais intensa para o setor rural, vai de encontro à teoria do Capital Humano que demonstra que a atividade econômica depende, além da infraestrutura e do capital físico, de pessoas educadas. A Abordagem das Capacitações ressalta que esse processo, somado ao dinamismo econômico, proporciona também às famílias a ampliação das possibilidades de escolhas e a melhora na participação e envolvimento social ${ }^{18}$.

TABELA 4. COEFICIENTES I DE MORAN MULTIVARIADO

\begin{tabular}{|c|c|c|}
\hline Variáveis & Região & Tde Moran \\
\hline $\operatorname{IDF}(\mathrm{U} / \mathrm{R})$ & & 0,7855 \\
\hline $\operatorname{IDF}(\mathrm{U}) /$ percentual IDF(U/R) & & $-0,6048$ \\
\hline \multirow{2}{*}{ Acesso ao Trabalho / Acesso ao Conhecimento } & Rural & 0,6929 \\
\hline & Urbano & 0,4575 \\
\hline
\end{tabular}

FONTE: elaboração própria a partir dos dados da pesquisa. Todos os coeficientes apresentaram significância estatística superior a 0,001\%, obtida através de 999 permutações aleatórias.

Os indicadores globais de correlação espacial fornecem um único valor como medida da associação espacial para as microrregiões do Estado de Minas Gerais. Entretanto, dentro desse conjunto de microrregiões, podem ocorrer diferentes níveis e regimes de associação espacial. Neste sentido, para examinar os padrões de correlação espacial em maior detalhe, no contexto multivariado, serão descritos no tópico a seguir indicadores locais que produzem um valor específico para cada microrregião, permitindo, desta forma, a identificação de agrupamentos.

\subsubsection{Diagrama de Dispersão e Indicadores Locais de Associação Espacial (LISA)}

O diagrama de dispersão, além da declividade da reta de regressão da variável de interesse em relação à média dos atributos dos vizinhos, que representa $\mathrm{a}$ medida global de associação linear, fornece a informação de quatro tipos de

18 Segundo Sen (2004), os benefícios da educação superam sua função de Capital Humano na produção de bens. A perspectiva mais ampla da Abordagem das capacitações inclui funções adicionais, tais como a maior participação na vida social da comunidade. 
associação linear espacial: Alto-Alto (AA), Baixo-Baixo (BB), Alto-Baixo (AB) e Baixo-Alto (BA). O mapa de Cluster LISA ilustra essas quatro categorias de associação espacial, combinando a informação do diagrama de dispersão com o mapa de significância das medidas de associação local. Visando aprofundar a análise da interação espacial das áreas urbanas com as regiões rurais em seu entorno, são apresentados o diagrama de dispersão e o mapa de Cluster para relações multivariadas da Tabela 4, utilizando, para tanto, o nível de significância de $5 \%$, ou seja, os clusters persistentes a este nível de significância mereceram maior atenção.

O diagrama de dispersão, anexo do trabalho, Figura A.2, e o mapa de cluster LISA, descrito na Figura 6, ao analisarem o Índice de Desenvolvimento da Família Urbana associado ao Índice Rural, demonstram, respectivamente, que a maioria das microrregiões está localizada nos quadrantes Alto-Alto (AA) e Baixo-Baixo (BB), resultando em uma correlação positiva com o coeficiente I de Moran de 0,78. Esse resultado, interpretado anteriormente, significa que as regiões urbanas com alto nível de IDF são vizinhas de regiões rurais com alto nível para esse mesmo atributo e, por outro lado, as regiões urbanas com baixo IDF são vizinhas também de regiões rurais com baixo nível do IDF. No mapa de cluster, destacam-se dois grandes agrupamentos. O primeiro, AltoAlto (AA), é formado basicamente pelas microrregiõeos do Triângulo Mineiro (Ituiutaba, Frutal, Uberlândia, Uberaba, Patrocínio, Araxá e Patos de Minas) e Sul de Minas (Passos, Varginha, Alfenas, São Sebastião do Paraíso, Santa Rita do Sapucaí, Pouso Alegre e Possos de Caldas), e ainda uma microrregião da região Central Mineira (Bom Despacho), uma da Metropolitana (Pará de Minas) e três do Oeste de Minas (Piuí, Formiga e Divinópolis). O segundo agrupamento, Baixo-Baixo (BB), localizado no outro extremo do estado, é formado pelas regiões Norte de Minas (Januária, Grão Mogol, Salinas, Bocaiuva, Montes Claros e Janaúba), Jequitinhonha (Diamantina, Capelinha, Araçuaí, Pedra Azul e Almenara), Vale do Mucuri (Teófilo Otoni, Nanuque), Vale do Rio Doce (Governador Valadares, Peçanha e Guanhães) e Metropolitana (Conceição do Mato Dentro). 
FIGURA 6. MAPA DE CLUSTER LISA PARA O ÍNDICE DE DESENVOLVIMENTO DA FAMÍLIA URBANA (IDRU) ASSOCIADO AO ÍNDICE RURAL (IDFR)

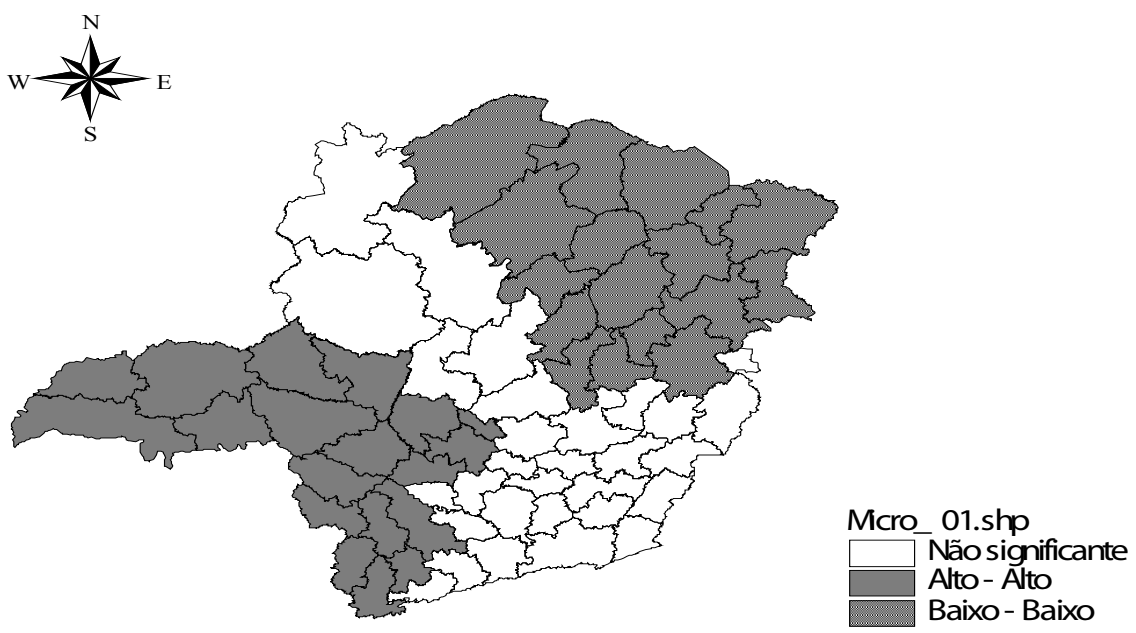

FONTE: os cálculos, utilizando os dados da pesquisa, foram desenvolvidos no software GEODA.

O Diagrama de dispersão, figura A.3, e o mapa de cluster LISA para o Índice de Desenvolvimento da Família Urbano associado à diferença percentual entre os índices de desenvolvimento das famílias urbana e rural, descrito na Figura 7, complementam a análise anterior. O diagrama de dispersão, com a maioria das microrregiões nos quadrantes Baixo-Alto (BA) e Alto-Baixo (AB), resulta em correlação negativa com o I de Moran bivariado assumindo o nível de - o,6o. O mapa demonstra a formação de três Clusters. O primeiro, AltoBaixo (AB), formado pelas regiões com alto nível de IDF vizinhas de regiões que apresentam pequena diferença entre o IDF urbano e rural, é composto pelas microrregiões do Triângulo (Uberlândia, Patrocínio, Araxá e Patos de Minas), Sul de Minas (Passos, Varginha, Alfenas, São Sebastião do Paraíso), Central Mineira (Bom Despacho), Metropolitana (Pará de Minas) e Oeste de Minas (Piuí, Formiga e Divinópolis). O segundo cluster, caracterizado como Baixo-Baixo (BB) e localizado ao lado do primeiro agrupamento, formado pelas regiões com baixo nível de IDF vizinhas de regiões que apresentam pequena diferença entre o IDF urbano e rural, é composto pelas microrregiões de Paracatu e Três Marias. O terceiro cluster, localizado no norte do estado, caracterizado como Baixo-Alto (BA), formado por regiões com baixo IDF cercadas por regiões com grande diferença entre o IDF urbano e rural, é composto pelas microrregiões do Jequitinhonha (Capelinha, Araçuaí e Almenara), Norte de Minas (Bocaiúva, Grão Mogol e Janaúba), Vale do Mucuri (Teófilo Otoni, Nanuque), Vale do Rio Doce (Governador Valadares, Peçanha, Guanhães e Mantena) e Metropolitana (Conceição do Mato Dentro). As microrregiões Ipatinga e Barbacena, caracterizadas como Alto-Alto (AA), por estarem dispersas não chegam a formar um agrupamento propriamente dito. 
FIGURA 7. MAPA DE CLUSTER LISA PARA O ÍNDICE DE DESENVOLVIMENTO DA FAMÍLIA URBANA (IDRU) ASSOCIADO À DIFERENÇA PERCENTUAL ENTRE OS ÍNDICES DE DESENVOLVIMENTO DAS FAMÍLIAS URBANA E RURAL (IDFP).

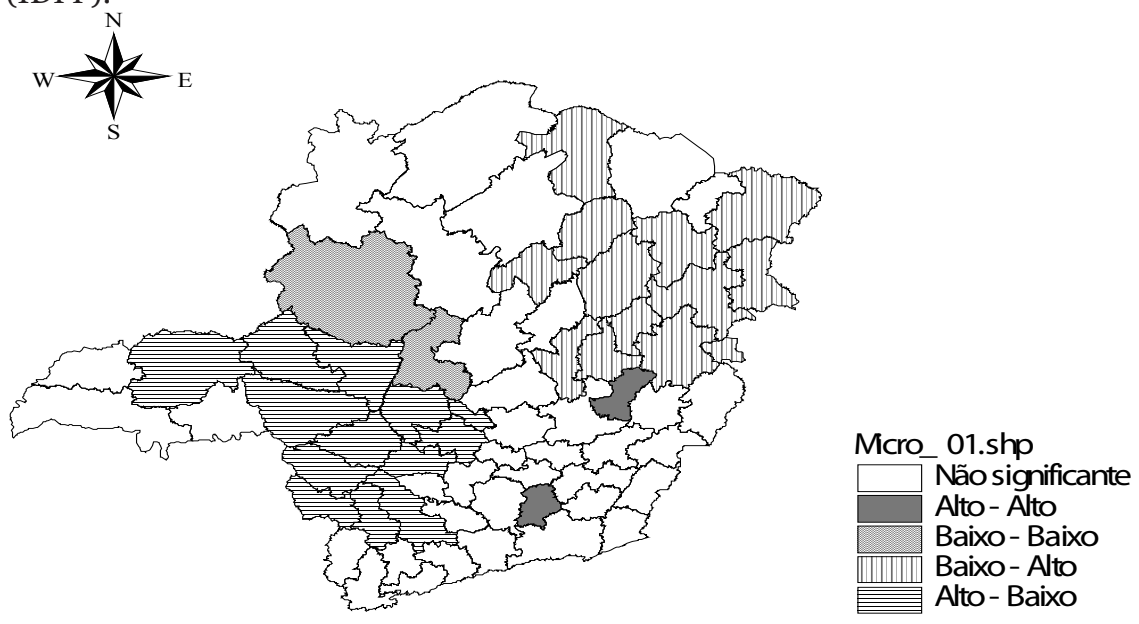

FONTE: os cálculos, utilizando os dados da pesquisa, foram desenvolvidos no software GEODA.

As Figuras 8 e 9 apresentam, respectivamente, os mapas de cluster LISA para a correlação bivariada das dimensões Acesso ao Trabalho associado ao Acesso ao conhecimento para as regiões urbana e rural. Os diagramas de dispersão estão descritos, no anexo do trabalho, na Figura A.4. A maioria das mesorregiões se encontra, nos diagramas de dispersão, nos quadrantes Alto-Alto (AA) e Baixo-Baixo (BB), com correlação espacial positiva, ou seja, regiões com alto acesso ao trabalho são vizinhas de regiões com alto acesso ao conhecimento e, por sua vez, as de baixo acesso ao trabalho vizinhas das de baixo acesso ao conhecimento. É interessante destacar que esse processo é mais intenso na região rural, com o I de Moran assumindo valor de 0,69, enquanto a região urbana apresenta correlação de 0,46 . 
FIGURA 8. MAPA DE CLUSTER LISA PARA O ACESSO AO TRABALHO URBANO (ATU) ASSOCIADO AO ACESSO AO CONHECIMENTO URBANO (ACU).
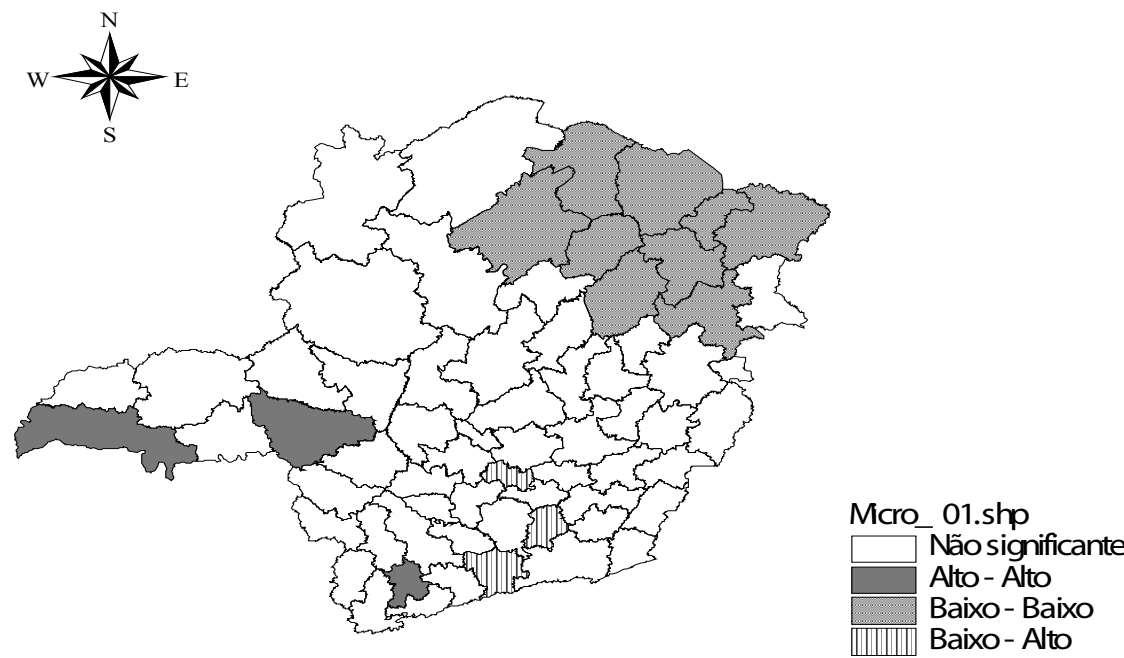

FONTE: os cálculos, utilizando os dados da pesquisa, foram desenvolvidos no software GEODA.

FIGURA 9. MAPA DE CLUSTER LISA PARA O ACESSO AO TRABALHO RURAL (ATR) ASSOCIADO AO ACESSO AO CONHECIMENTO RURAL (ACR).

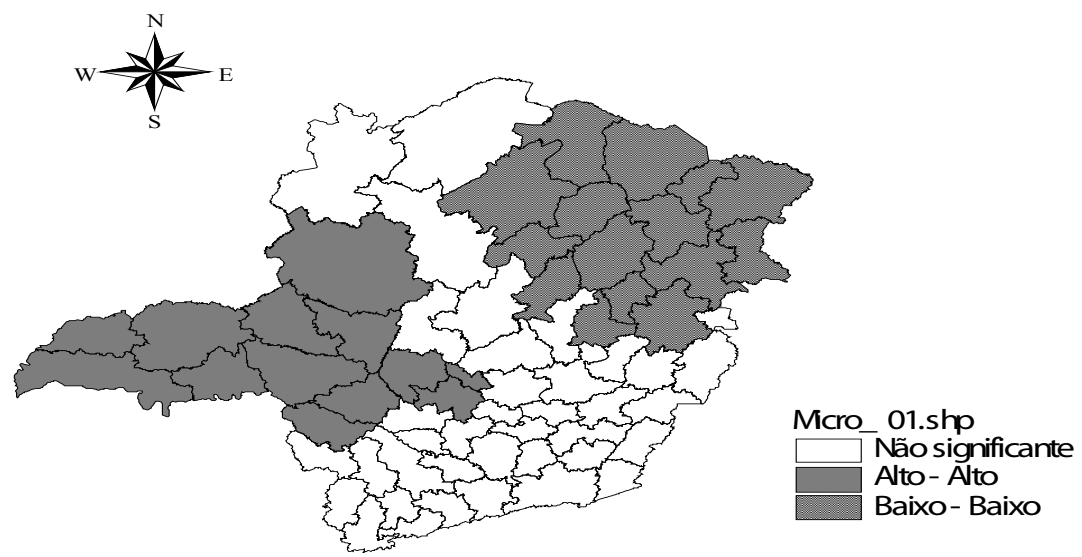

FONTE: os cálculos, utilizando os dados da pesquisa, foram desenvolvidos no software GEODA.

No mapa da região urbana, identificou-se a formação de apenas um cluster Baixo-Baixo (BB), formado por quatro microrregiões do Norte de Minas (Grão Mogol, Salinas, Montes Claros e Janaúba) e Jequitinhonha (Capelinha, Araçuaí, Pedra Azul e Almenara), e uma do Vale do Mucuri (Teófilo Otoni). As microrregiões de Frutal, Araxá e Santa Rita do Sapucaí, com correlação local 
Alto-Alto (AA), e as de Itaguara, Andrelândia e Barbacena, com correlação Baixo-Alto (BA), na medida em que estão dispersas no estado, não chegam a caracterizar a formação de Clusters.

No mapa para a região rural, verificou-se a formação de dois Clusters. O primeiro, refere-se ao Alto-Alto (AA), formado por todas as microrregiões do Triângulo Mineiro (Ituiutaba, Frutal, Uberlândia, Uberaba, Patrocínio, Araxá e Patos de Minas), uma do Noroeste de Minas (Paracatu), uma da região Central (Bom Despacho), duas do Oeste de Minas (Piui e Divinópolis), uma do Sul de Minas (Passos) e uma da Região Metropolitana (Pará de Minas). O segundo cluster refere-se ao Baixo-Baixo (BB), formado por todas a microrregiões do Jequitinhonha (Diamantina, Capelinha, Araçuaí, Pedra Azul e Almenara) e Vale do Mucuri (Teófilo Otoni e Nanuque), três do Vale do Rio Doce (Peçanha, Guanhães e Governador Valadares) e cinco do Norte de Minas (Grão Mogol, Bocaiúva, Salinas, Montes Claros e Janaúba), refere-se ao Baixo-Baixo (BB).

\section{Considerações finais}

O trabalho, ao utilizar a família como unidade de análise do desenvolvimento humano, procurou enfatizar a dimensão coletiva da abordagem das capacitações, assumindo que o convívio de seus membros pode gerar externalidades positivas e negativas que condicionam a liberdade de escolha dos indivíduos e a possibilidade de acesso a importantes atributos do desenvolvimento humano. Outro aspecto considerado no trabalho foi a dimensão territorial. As condições de vida e o bem-estar das famílias estão condicionados à realidade socioeconômica e geográfica das regiões em que estão inseridos. Neste sentido, analisou-se comparativamente o nível do bem estar das famílias rurais e urbanas para as sessenta e seis microrregiões do estado.

As famílias que residem em domicílios urbanos apresentaram, para todo o estado, condições de vida superior às famílias do meio rural. A maior discrepância entre as condições de vida ocorreu nas microrregiões localizadas no Nordeste, Norte, Jequitinhonha e Vale do Mucuri. Esse comportamento demonstra que, de certa forma, o processo de urbanização-extensiva é mais intenso no sul do estado, enquanto no Norte e na Zona da Mata persiste ainda uma grande diferença entre as condições de vida das famílias urbanas e rurais. Verificou-se um desequilíbrio entre as seis dimensões do IDF, mais intenso na região rural, com condições desfavoráveis principalmente para o acesso ao conhecimento e o acesso ao trabalho. Cabe ressaltar que essas dimensões, possibilitam ganhos materiais efetivos em uma economia de mercado. Através da educação e do emprego os indivíduos ampliam as possibilidades de escolhas genuínas, aumentam a autoestima e, entre outros ganhos, podem melhorar a fluência no campo social. O teste de autocorrelação espacial I de Moran 
apresentou valor positivo para o IDF e suas seis dimensões, tanto para a região urbana quanto rural, demonstrando que as microrregiões com altos ou baixos indicadores tendem a se aglomerar no mesmo espaço. No caso específico do teste bivariado, observou-se que as regiões com alto acesso ao trabalho são cercadas por regiões com altos indicadores de acesso ao conhecimento e, por sua vez, as regiões com baixo acesso ao trabalho são circundadas por regiões com pouco acesso ao conhecimento. Essa correlação positiva, mais intensa para o setor rural, corrobora a teoria do capital humano que demonstra que a atividade econômica depende, além da infraestrutura e do capital físico, de pessoas educadas. A abordagem das capacitações ressalta que esse processo, somado ao dinamismo econômico, proporciona também às famílias a ampliação das possibilidades de melhora na participação e envolvimento social como forma de reverter as desigualdades regionais.

O trabalho demonstrou um quadro de forte desigualdade no desenvolvimento humano das famílias mineiras, tanto no que diz respeito às condições de vida entre as regiões urbana e rural, quanto nas disparidades entre as regiões sul e norte do estado. Sem querer entrar no mérito da avaliação de políticas públicas, na medida em que o escopo do trabalho não aborda este tema, vale ressaltar que a intervenção do setor público com políticas de desenvolvimento de cunho exclusivista, as quais não levam em conta as regiões urbana e rural como espaço contíguo, onde, na maioria das vezes, como se observou no presente trabalho, o dinamismo do primeiro é a fonte do dinamismo do segundo, pode ter contribuído para o quadro de desigualdade entre as áreas urbana e rural no Estado de Minas Gerais.

\section{Referências}

ALMEIDA, Eduardo Simões de. (2007) Econometria Espacial Aplicada. FEA/ UFJF. Apostila.

ANSELIN, L \& SYABRI, I \& SMIRNOV, O. (2003) Visualizing multivariate spatial correlation with dynamically linked Windows. University of Illinois, Mimeo.

ANSELIN, L. (1995) “Local Indicators of Spatial association - LISA.” Geographical Analyses 27(2).

BAGOLIN, I. P.(2005) Da renda à capacitações: analisando e avaliando o desenvolvimento humano. Porto Alegre: Tese de Doutorado em Economia, Universidade Federal do Rio Grande do Sul

BARROS, R. P. \& CARVALHO, M. \& FRANCO, S. (2003) Índice de desenvolvimento da família (IDF). IPEA: Rio de Janeiro. Texto para discussão 986.

CLIFF, A. D. \& ORD, J. K. (1981) Spatial processes: models and applications. London: Pion.

DEL GROSSI, M. E. \& GRAZIANO, J. S. (2002) O uso das PNADs para áreas rurais. Rio de Janeiro: IPEA. Texto para discussão. 
IBGE. INSTITUTO BRASILEIRO DE GEOGRAFIA E ESTATÍSTICA. (2005) Censo Demográfico de 2000. Rio de Janeiro: IBGE.

GONÇALVES, E. (2005) Distribuição Espacial da Atividade Inovadora Brasileira: Uma Análise Exploratória. Belo Horizonte: UFMG. Texto para discussão CEDELEPLAR.

KAGEYAMA, A. (2003) “Os Rurais e os agrícolas de São Paulo no Censo de 20oo”. Campinas: IE/UNICAMP. Texto para discussão.

GRAZIANO DA SILVA, J \& DEL GROSSI, E. (2001) O novo rural brasileiro: uma atualização para 1992-98. Unicamp. Texto para discussão.

LE GALLO, J. \& ERTHUR, C. (2003) "Exploratory special data analysis of the distribution of rergional per capita GDP in Europe, 1980 a 2001." Papers in Regional Science 82(2): 175-201.

MATTOS, E. J. (2006) Pobreza rural no Brasil: um enfoque comparative entre a abordagem monetária e a abordagem das capacitações. Porto Alegre: Dissertação de mestrado em desenvolvimento rural. Universidade Federal do Rio Grande do Sul.

MEDEIROS, M. (2000) “A importância de se conhecer melhor as famílias para a elaboração de políticas sociais na América Latina.” Planejamento e Políticas Públicas 22.

MONTE-MÓR, R. L. (1994) “Urbanização extensiva e novas lógicas de povoamento: um olhar ambiental.” In SANTOS, M. A.\& SILVEIRA, M. L. (ed.). Território: globalização e fragmentação. São Paulo: Hucitec/Anpur.

ROCHA, L. E. V. \& SANTOS, G. C. (2007) "Pobreza e concentração de renda na agricultura: Uma análise para as mesorregiões do Estado de Minas Gerais Brasil.” In XXVII International Congress Latin American Studies Association, Montreal 2007.

ROCHA, L. E. V. \& MOREIRA, R. B. \& SANTOS, G. C. (2008) “Índice de Desenvolvimento da Família (IDF): uma análise para as microrregiões e grupos demográficos do Estado de Minas Gerais.” In Fórum BNB de Desenvolvimento - XIII Encontro Regional de Economia, Fortaleza (CE).

SILVA, J. G. (2001) “Quem precisa de uma estratégia de desenvolvimento?” In SILVA, J.G. \& WEID, J. M. \& BIANCHINI, V. O Brasil rural precisa de uma estratégia de desenvolvimento. Núcleos de Estudos Agrários e de Desenvolvimento.

SEN, AMARTYA. (2001) Desigualdade reexaminada. Rio de Janeiro: Record.

SEN, AMARTYA. (2009) "Capital Humano e Capacidade Humana." URL: www. redvertice.com/fer. 2004. Acesso em: 20/02/2009.

SEN, AMARTYA. (1999) Development as freedom. New York: Anchor Books.

Recebido em: 14 de agosto de 2009

Primeira resposta em: 21 de janeiro de 2010

Aceite em: 28 de julho de 2010 
Neste tópico, primeiramente, apresenta-se a Figura A.1 que identifica a composição das mesorregiões e a localização das microrregiões no mapa do Estado de Minas Gerais. E, posteriormente, as figuras A.2, A.3 e A.4, que descrevem os diagramas de dispersão

\section{FIGURA A.1. COMPOSIÇÃO DAS MESORREGIÕES E LOCALIZAÇÃO DAS MI- CRORREGIÕES DO ESTADO DE MINAS GERAIS}

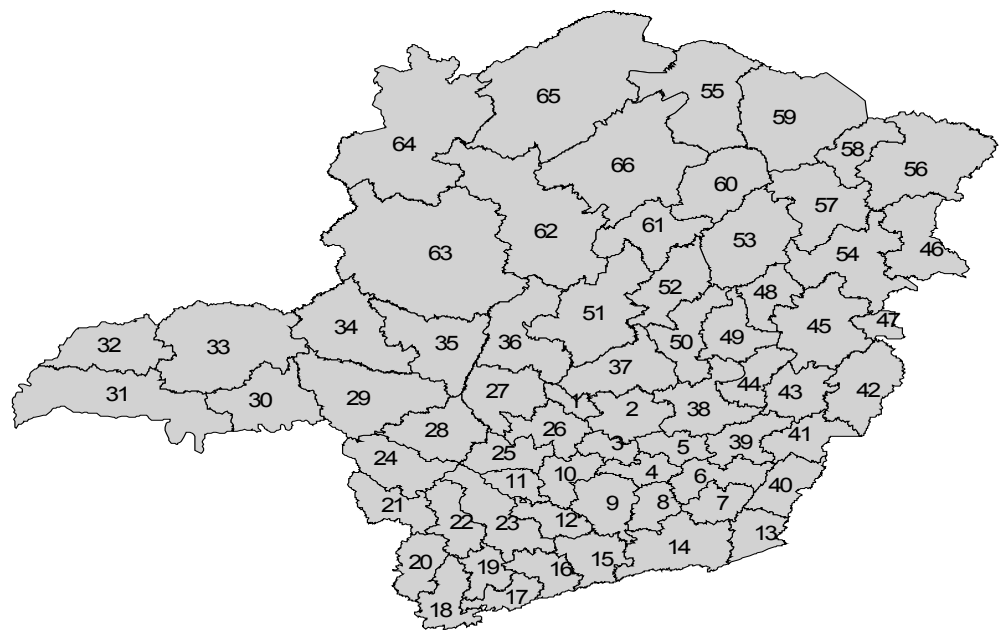

Campo das Vertentes: (8) Barbacena, (9) São João del Rei, (12) Lavras. Central Mineira: (27) Bom Despacho, (36) Três Marias, (51) Curvelo. Jequitinhonha: (52) Diamantina, (53) Capelinha, 56) Almenára, (57) Araçuaí, (58) Pedra Azul. Metropolitana de Belo Horizonte: (1) Pará de Minas, (2) Belo Horizonte, (3) Itaguara, (4) Conselheiro Lafaiete, (5) Ouro Preto, (37) Sete Lagoas, (38) Itabira, (50) Conceição do Mato Dentro. Noroeste de Minas: (63) Paracatu, (64) Unaí. Norte de Minas: (55) Janaúba, (59) Salinas, (60) Grão Mogol, (61) Bocaiúva, (62) Pirapora (65) Januária, (66) Montes Claros. Oeste de Minas: (10) Oliveira, (11) Campo Belo, (25) Formiga, (26) Divinópolis, (28) Piuí. Sul/ Sudoeste de Minas: 15) Andrelândia, (16) São Lourenço, (17) Itajubá, (18) Pouso Alegre, (19) Santa Rita do Sapucaí, (20) Poços de Caldas, (21) São Sebastião do Paraíso, (22) Alfenas, (23) Varginha, (24) Passos. Triângulo Mineiro/Alto Paranaíba: (29) Araxá, (30) Uberaba, (31) Frutal, (32) Ituiutaba, (33) Uberlândia, (34) Patrocínio, (35) Patos de Minas. Vale do Mucuri: (46) Nanuque, (54) Teófilo Otoni. Vale do Rio Doce: (42) Aimorés, (43) Caratinga, (44) Ipatinga, (45) Governador Valadares, (47) Mantena, (48) Peçanha, (49) Guanhães. Zona da Mata: (6) Viçosa, (7) Ubá, (13) Cataguases, (14) Juiz de Fora, (39) Ponte Nova, (40) Muriaé, (41) Manhuaçu. 
FIGURA A.2. DIAGRAMA DE DISPERSÃO PARA O ÍNDICE DE DESENVOLVIMENTO DA FAMÍITA ITRRANA (INRIT) ASSOCIANO AO ÍNDICE RURAL (IDFR).

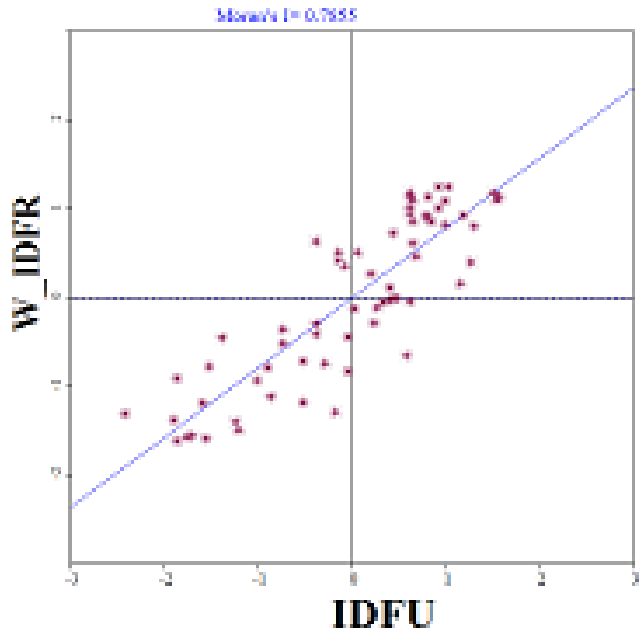

FIGURA A.3. DIAGRAMA DE DISPERSÃO DO ÍNDICE DE DESENVOLVIMENTO DA FAMÍLIA URBANA (IDRU) ASSOCIADO À DIFERENÇA PERCENTUAL ENTRE OS ÍNDICES DE DESENVOLVIMENTO DAS FAMÍLIAS URBANA E RURAL (IDFP).

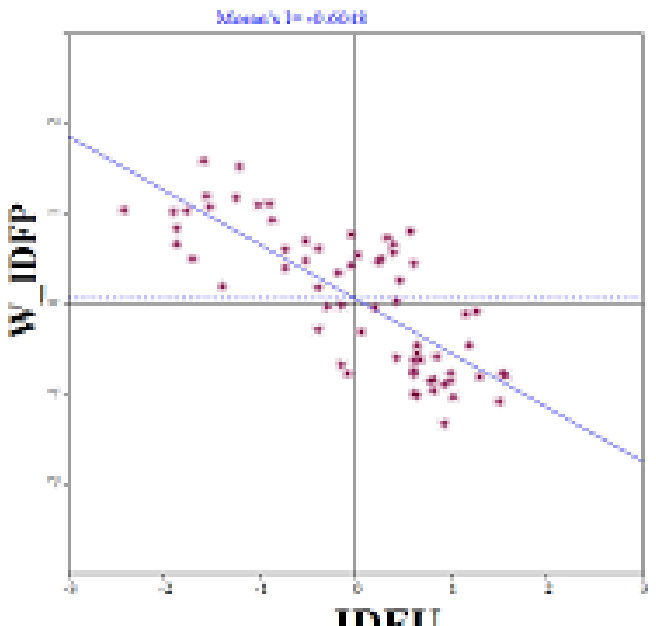


ROCHA, L. E. V. \& FONTES, R. M. O. Disparidades do desenvolvimento urbano...

FIGURA A.4. DIAGRAMAS DE DISPERSÃO DO ACESSO AO TRABALHO ASSOCIADO AO ACESSO AO CONHECIMENTO, RESPECTIVAMENTE PARA AS REGIÕES RURAL (ATR) E URBANA (ATU).

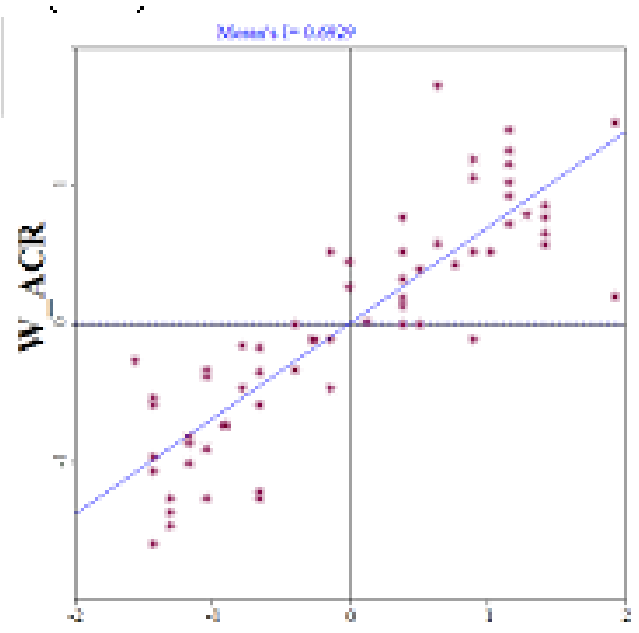

ATR

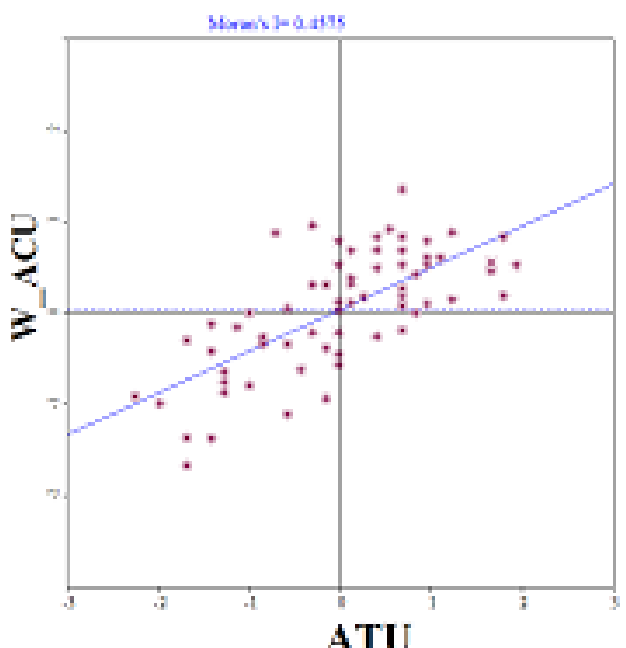

